\title{
Influential factors and barriers to opt for the uptake of HIV testing among the adult population at HIV-care admission in an area in the DR Congo: What can we learn?
}

\author{
Koy Tshingani ${ }^{1}$, Michel Aloni Ntetani ${ }^{2}$, Gabriel V. Nsakala ${ }^{3}$, Mathilde B. Ekila ${ }^{4}$, Philippe Donnen ${ }^{5}$, \\ Michèle Dramaix-Wilmet ${ }^{1}$ \\ ${ }^{1}$ Centre de recherche en Epidémiologie, Biostatistiques et Recherche Clinique, Ecole de santé Publique, Université Libre \\ de Bruxelles, Brussels, Belgium \\ ${ }^{2}$ Department of Pediatrics, University Hospital of Kinshasa, Faculty of Medicine, University of Kinshasa, Kinshasa, \\ Democratic Republic of Congo \\ ${ }^{3}$ Department of Health Sciences, National Pedagogical University of Kinshasa (UPNK), Binza-Kinshasa, Democratic Republic \\ of Congo \\ ${ }^{4}$ Division of Infectious Diseases, University Hospital of Kinshasa, Faculty of Medicine, University of Kinshasa, Kinshasa, \\ Democratic Republic of Congo \\ ${ }^{5}$ Centre de recherche en Politique et systèmes de santé - Santé internationale, École de santé publique, Université Libre \\ de Bruxelles, Brussels, Belgium
}

\begin{abstract}
Introduction: To reverse the trends of the acquired immune deficiency syndrome (AIDS) epidemic, reinforcement of personal protection and antiretroviral treatment (ART) initiation at right time are needed. The aim of the study was, a decade after expanding AIDS medical care, to explore facilitating factors or those contributing to uptake or delay of human immunodeficiency virus (HIV) testing among individuals who access voluntary counselling and testing (VCT) in an urban area of the Democratic Republic of Congo (DRC).

Material and methods: A cross-sectional survey carried out among individuals attending three VCT centres in Kinshasa, DRC.

Results: A total of 388 individuals with mean age 42 (9.4) years were included. Among them 34\% were married, and 96\% were living at home. Morbid and social events were the most important reasons cited for uptake of HIV testing in urban areas. Among the most common barriers of the HIV testing observed, stigma was the first reason significantly prevalent cited among man while fear to know the HIV status, ignorance of seropositivity concepts and the existence of VCT screening were prevalent among females. Conclusions: Two main events influencing the uptake of HIV testing and commonly known barriers to this were cited. These results generate questions about a fringe of the population, and call for further research for improved prevention policy.
\end{abstract}

HIV AIDS Rev 2017; 16, 4: 220-225 DOI: https://doi.org/10.5114/hivar.2017.71934

Key words: voluntary counselling and testing, HIV prevention, barriers of HIV testing, HIV/AIDS, Democratic Republic of Congo.

Address for correspondence: Dr. Koy Tshingani, Centre de recherche en Epidémiologie, Biostatistiques et Recherche Clinique, Ecole de santé Publique, Université Libre de Bruxelles, Route de Lennik nº08, 1070 Anderlecht, Belgium, e-mail: tshingani.koy@ulb.ac.be
Article history:

Received: 09.03.2017

Received in revised form: 06.07.2017

Accepted: 04.10.2017

Available online: 30.11 .2017
International Journal of HIV-Related Problems

HIV \& AIDS

$R$ e vi e w 


\section{Introduction}

Acquired immune deficiency syndrome (HIV/AIDS) remains one of the most devastating diseases worldwide. Great progress has been made in the fight against HIV/AIDS in the world, aiming to completely turn the tide of the epidemic and give to everyone more ways to prevent transmission of the virus, especially in an endemic area. However, according to the United Nations Programme on HIV/ AIDS (UNAIDS) report stated in 2015, a significant gap remains in knowledge of serologic status and access to HIV treatment worldwide: of the 36.9 million people living with HIV (PLHIV), 17.1 million ignore their serologic status and need to be reached with the HIV-testing services. In addition, around 22 million people need access to HIV treatment [1]. Recently it has been reported that scientific results and the epidemiological observations converge for a profound renewal of strategies of fight against HIV/AIDS [2]. There is a need to formulate strategies in respect of prevention and screening, available tools able to reduce sensibly trend of the epidemic.

In the Democratic Republic of Congo (DRC), HIV remains a major public health problem. According to World Health Organisation (WHO) global estimations in 2013, $1,034,086$ people more than 15 years of age are HIV infected, and the majority of them are estimated to be women [3]. In this country, sexual transmission remains the major cause of virus contamination [4]. Furthermore, HIV screening is not a common practice. The diagnosis is then delayed $[5,6]$. The use of antiretroviral therapy (ART) has significantly improved the life expectancy of people infected with HIV $[7,8]$. This treatment helps patients to deal with doubt, anxiety and perplexing questions during the post-test period. Despite this progress, HIV screening remains a crucial element of prevention through which patients may know their serologic status and can be considered for HIV care. To optimise prevention in high HIV prevalence settings, strategies as the opt-in or the complementary opt-out strategy are advised. During an opt-in strategy, patient's agreement to undertake HIV screening is obtained after counselling. This strategy is initiated by health providers in healthcare settings, whereas during the complementary opt-out strategy, the patient's consent is implicit by the fact that he/she is seeking care [9]. In addition, promotion of behavioural change, fight against HIV transmission from mother to child, HIV testing, and ART are also advocating amplified prevention [10]. Socio-behavioural and contextual factors such as access to HIV prevention services, education and sexual and reproductive health service, poverty, food insecurity, violence, and access at the right time to ART have been identified as barriers of HIV testing in literature [11, 12]. In this condition, types of HIV prevention, HIV testing, and counselling services delivered may influence the responses of patients to uptake. Understanding the circumstances of consent to uptake of HIV testing and their correlation, such as the confidentiality or reducing fear of disclosure of HIV information after patients receive their test results, remains unknown in our midst.

The aim of the study was, two decades after the expansion of AIDS medical care and ART, to explore the factors leading or those contributing to delay the uptake of HIV testing in an urban area of the DRC.

\section{Material and methods}

\section{Study design and site}

A cross-sectional study was carried out in three voluntary counselling and testing (VCT) settings situated at the outpatient centres, in North, West and South Kinshasa, DRC in March 2011: respectively, the VCT of Kasa-Vubu, Mbinza-ozone, and Ndjili. Those VCT settings were selected for this study because they organised both preventive and curative treatments among individuals who come to seek health care on their own initiative, or those referred by the HIV awareness campaigns. A convenience sample of 388 PLHIV aged 18 years old or above, who agreed to participate in the study were included. The study population consisted of all individuals diagnosed with HIV infection at one of these centres and treated with ART. Late testing was defined as having an AIDS-defining illness at date of AIDS diagnosis or within one year of first positive HIV test.

\section{Data collection}

An anonymous, written, open questionnaire was developed in French, translated into Lingala (the predominant language in Kinshasa), and pre-tested and adapted during a pilot study of 35 patients who were not selected for this study. This questionnaire was administered by a trained nurse specialised in HIV/AIDS counselling and by a medical team at inception in the study. These questions included circumstances referred to the time before or at diagnosis (factors or first reasons cited that contributed to the HIV testing or those that delayed the HIV testing): i) sociodemographic data, including: age, marital status, educational level, the living environment (number of people living); ii) socioeconomic profiles categorised as low, middle, and high socioeconomic level of patients, were established according to the score of socioeconomic status (SSE) created taking into account their monthly household income, their properties (ownership), and their goods of comfort (availability of sanitary services, electricity, number of bedrooms); and iii) detailed medical information was collected from the patients' medical files: disease history, clinical status of the HIV testing. These collected variables were categorised: marital status as single (including those who were not in relationship, divorced, and widower) or married (those in a relationship), the educational level as primary, secondary, or higher (for those who had the upper or university level), and the living environment was categorised as patients living alone or in a family home. 


\section{Ethics statement}

The institutional review boards and the Ethics Committee of the University of Kinshasa approved the protocol of the study (ESP/CE/005/2010), which was conducted in compliance with the principles of the Helsinki Declaration II. Patients were informed about the research purposes and gave written informed consent. The respondents were informed that they could withdraw from the study at any time without further obligation. Confidentiality of data was assured.

\section{Data management}

Baseline characteristics were described as means, standard deviations, and percentages. Chi-squared, or Fisher's exact tests were performed to compare proportions of the variables first reasons cited facilitating the uptake or delaying the HIV screening according to sociodemographic. All statistical analyses were performed using the Statistical Package for Social Sciences (SPSS) version 22.

\section{Results}

In total 388 patients were interviewed among all individuals diagnosed with HIV-infection and treated with ART at the outpatients' clinic and VCT: 106 (27\%) were male and $282(73 \%)$ female. Overall, the mean age was $42 \pm 9.4$ years. Married interviewees were most represented (34\%). The majority of interviewees were living with family $(96 \%)$. The secondary or higher and middle socioeconomic levels were highly represented. Other details are shown in Table 1.

Table 1. Sociodemographic characteristics of patients at inception

\begin{tabular}{|c|c|c|c|}
\hline Variables & $n$ & $\%$ & Mean (SD) \\
\hline Age & 388 & & $42.0(9.4)$ \\
\hline \multicolumn{4}{|l|}{ Gender } \\
\hline Female & 282 & 73 & \\
\hline Male & 106 & 27 & \\
\hline \multicolumn{4}{|l|}{ Marital status } \\
\hline Single (not in relationship) & 255 & 66 & \\
\hline Married & 133 & 34 & \\
\hline \multicolumn{4}{|l|}{ Education levels } \\
\hline Non-literate or primary & 33 & 9 & \\
\hline Secondary or higher education & 355 & 91 & \\
\hline \multicolumn{4}{|l|}{ Socioeconomic status } \\
\hline Poor & 122 & 31 & \\
\hline Average or comfortable & 266 & 69 & \\
\hline \multicolumn{4}{|l|}{ Living environment } \\
\hline Alone & 15 & 4 & \\
\hline With family & 373 & 96 & \\
\hline
\end{tabular}

Almost three quarters (71\%) of the interviewees had an AIDS-defining illness diagnosed concurrently with HIV, most commonly Mycobacterium tuberculosis (46\%), atypical pneumonia, and candidiasis (22\%), wasting syndrome (13\%), atypical dermatitis and zona (4\%), recurrent salmonella (4\%), and persistent gastroenteritis. Twelve percent of the interviewees had felt at risk of HIV-infection before diagnosis because of having morbid episodes of spouse (7\%) or his/her death. Social events such as a wedding event or travel abroad represented $19.7 \%$ of circumstances during which patients included in our study found out about their HIV-positive status. Access to HIV-testing without a proven interest was a rare event. Only $2 \%$ of other details are shown in Table 2. The first reason cited enabling uptake of HIV testing because of the feeling at risk of HIV-infection before diagnosis "morbid episode of sexual partner" was significantly more prevalent among patients living alone while the death of sexual partner, social event, and voluntary uptake of HIV testing were significantly higher among patients living in a family environment (Table 3). In our study, the most commons barriers of early presentation or in absence of AIDS-defining illness to uptake of HIV test-

Table 2. First reason facilitating the uptake of HIV testing

\begin{tabular}{l|c|c}
\hline Reason cited for HIV testing & $n=335$ & $\%$ \\
\hline Morbid episode & 238 & 71 \\
\hline Tuberculosis & 109 & 46 \\
\hline Atypical pneumonia and candidiasis & 53 & 22 \\
\hline Wasting syndrome & 30 & 13 \\
\hline Recurrent Salmonella & 10 & 4 \\
\hline Atypical dermatitis and zona & 6 & 3 \\
\hline Persistent gastroenteritis & 30 & 13 \\
\hline Morbid episode of sexual partner & 23 & 7 \\
\hline Death of sexual partner & 16 & 5 \\
\hline Social event & 49 & 15 \\
\hline Voluntary testing & 9 & 2 \\
\hline
\end{tabular}

Table 3. First reason cited for HIV testing uptake according to sociodemographics

\begin{tabular}{l|c|c|c|c|c}
\hline \multirow{2}{*}{$\begin{array}{l}\text { Reason cited } \\
\text { for HIV testing }\end{array}$} & \multicolumn{4}{|c|}{ Living environment } & \multirow{2}{*}{$*$} \\
\cline { 2 - 5 } & \multicolumn{2}{|c|}{ Alone } & \multicolumn{2}{|c|}{ In a family } & \multirow{2}{*}{$p$} \\
\cline { 2 - 5 } & $n$ & $\%$ & $n$ & $\%$ & \\
\hline Morbid episode & 10 & 71.4 & 228 & 71 & \multirow{2}{*}{$0.036^{*}$} \\
\hline $\begin{array}{l}\text { Morbid episode } \\
\text { of sexual partner }\end{array}$ & 4 & 28.6 & 19 & 5.9 & \\
\hline Death of sexual partner & 0 & 0 & 16 & 5 & \\
\hline Social event & 0 & 0 & 49 & 15.3 & \\
\hline Voluntary testing & 0 & 0 & 9 & 2.8 & \\
\hline${ }^{*}$ Fisher exact & & & & &
\end{tabular}


Table 4. First reason cited for delay of HIV testing

\begin{tabular}{l|c|c}
\hline Reason cited for delay of HIV testing & $N=384$ & $\%$ \\
\hline Stigma & 171 & 45 \\
\hline Fear to know their HIV status & 139 & 36 \\
\hline Ignorance of the concept of seropositivity & 19 & 5 \\
\hline $\begin{array}{l}\text { Ignorance of the existence of voluntary } \\
\text { counselling and testing }\end{array}$ & 35 & 9 \\
\hline Lack of courage & 20 & 5 \\
\hline
\end{tabular}

Table 5. First reason cited for delay of HIV testing uptake according to sociodemographics

\begin{tabular}{l|c|c|c|c|c}
\hline \multirow{2}{*}{$\begin{array}{l}\text { Reason cited for delay } \\
\text { of HIV testing }\end{array}$} & \multicolumn{4}{|c|}{ Gender } & \multirow{2}{*}{\multicolumn{1}{|c}{}} \\
\cline { 2 - 5 } & $n$ & $\%$ & $n$ & $\%$ & \\
\cline { 2 - 5 } & 62 & 59.6 & 109 & 38.9 & $<0.001$ \\
\hline Stigma & 31 & 29.8 & 108 & 38.6 & \\
\hline $\begin{array}{l}\text { Fear to know their HIV } \\
\text { status }\end{array}$ & 1 & 1 & 18 & 6.4 & \\
\hline $\begin{array}{l}\text { lgnorance } \\
\text { of the concept } \\
\text { of seropositivity }\end{array}$ & 10 & 9.6 & 25 & 8.9 & \\
\hline $\begin{array}{l}\text { lgnorance of the } \\
\text { existence of voluntary } \\
\text { counselling and }\end{array}$ & & & & & \\
testing & & & & & \\
\hline Lack of courage & 0 & 0 & 20 & 7.1 & \\
\hline
\end{tabular}

ing were stigma (45\%) and fear to know their HIV status (36\%). Other details are presented in Table 4 . In addition, we observed among the first reason cited for delay of HIV testing that "stigma" was prevalent among males, while "fear to know the HIV status" and "ignorance of the concept of seropositivity and the existence of VCT" were prevalent among females (Table 5).

\section{Discussion}

In this study, we identified two main events leading directly to uptake of HIV testing among patients in an urban VCT two decades after the expansion of AIDS medical care et ART in DRC. The morbid and the social events. The morbid events concerned directly the applicant to the HIV testing at $71 \%$ or his/her partner at 5\%; another morbid event was in connection to death of a sexual partner in the medical history of the applicant at $7 \%$. Similar observations were found by other studies [13-15]. Social events such as travelling abroad or a wedding led to uptake of HIV testing in $15 \%$. Previous studies in the DRC reported similar observations $[5,16,17]$.

Because of AIDS-defining illness or other morbid events that inflict feeling of being at risk of HIV, the application to HIV testing after counselling seems to be more acceptable and causes less anxiety post-test because of the availability of ART. Patients are apparently more aware about their health problems and accept to break all barriers of HIV testing uptake. At the VCT, the integrated management of PLHIV illness is provided, included HIV prevention, psychosocial support, and ART. It is the place where an effective prevention strategy might be made for change of HIV-related sexual risk behaviours, thereby reducing HIV-related risk $[15,18,19]$.

The mean age of patients in this study was $42 \pm 9.4$ years and was in similarity with the frequently average age group encountered in endemic HIV regions [5, 16-24]. Furthermore, we noted in this present study a higher proportion of female patients than male. This phenomenon was observed in most other studies in DRC [5, 23-27], lack of adherence to preventive measures during sexual contact [28], and socio-cultural factors such as multiplicity of sexual partners and socioeconomic dependence of women in a context of poverty have been advocated for this [29-32].

Most of the patients in this study have known their HIV status at the AIDS stage with potential negative consequences at individual level or for the wider population: poorer response to ART, high costs of treating of these cases, high risk of onward transmission of HIV or death $[5,33]$, a patient living alone have a higher proportion of uptake of HIV testing according to a morbid event of a sexual partner. Feeling of fear of HIV risk, wider availability and possibility of therapy might seems to motivate this behaviour. However, patients living with their family presented a high proportion of uptake of HIV testing according to a death of sexual partner, or having a social event. This behaviour also seems to be motivated for the applicant by the psychological and economical supportive role of family than he/she receives, and because of the need of a rapid means of protection, refuting any prejudices of HIV.

Stigma and fear of knowing their HIV status, ignorance of the concept of seropositivity, and ignorance of the existence of VCT were the barriers to the uptake of HIV testing in this study. As previously reported in Sub-Saharan Africa countries [34], these factors were incriminated to be responsible for the psychological impact causing a delay the HIV care [35-37]. In addition, the inducing role of fear of the knowledge of HIV positive status has been advocated [34] and was considered as a key barrier of utilisation of HIV testing services in Sub-Saharan Africa [38]. In our study, stigma was prevalent among males (59.6\%) but fear of knowing the HIV status, and ignorance of the seropositivity concept and the existence of the VCT were prevalent among females (38.6\%, 6.4\%, 8.9\%, respectively). The explicit explanation of these was unclear from our data. Nevertheless, the reasons mentioned above and those in the literature $[39,40]$ might be considered for these factors as obstacles to HIV testing acceptance.

Our observation related to these results indicates that two decades after expanding AIDS medical care and ART, the factors involved in the voluntary HIV testing and their barriers, seems not to ensure universal access to the know- 
ing of HIV status to all those who need it at the appropriate time. It remains a shadow over HIV testing realities for people that have not undergone the two leading factors or events above cited. Consequently, several questions might arise concerning people within this gap: Are they aware about their serological status? How did the HIV phenomenon influence their behaviour and attitudes? Taking into account that in the DRC HIV transmission is mainly driven by sexual contact and adults in the sexually active age group older than 25 years are at increased risk of life-threatening HIV [17], requests for the screening test among pre-nuptial tests has been observed. This might be considered to amplify the knowledge of HIV status among those who want to marry and thus reduce the risk of HIV transmission among them in this country.

This study advocates, nevertheless, implementation of deeper studies for effective prevention strategies that maximise the effectiveness of a VCT and leads to the greatest uptake of HIV testing. These strategies might produce significant reductions of late presentation for an HIV diagnosis, and HIV-related sexual risk behaviours, thereby reducing HIVrelated risk [13].

\section{Limitations}

The main limitations of this study include the cross-sectional design within the VCT centres and convenience sample that might not allow some generalisation of observations to all people. Nevertheless, these results may serve as pointers of the reality gap existing between reasons leading to uptake of HIV testing after a decade of expansion of HIV care in VCT in urban areas. This phenomenon deserves more detailed research that calls for interventions to increase timely HIV testing, diagnosis, and therapeutic measures. This should include routine HIV testing during mobile campaigns, routine HIV testing as part of regular medical care, followed by immediate ART as a strategy for reduction or elimination of HIV transmission in this community on a large scale.

\section{Conclusions}

Two decades after the expansion of AIDS medical care and ART, a morbid event associated with the social events remains the most important influencing factor cited through which HIV testing was undertaken in urban areas. However, commonly known barriers to HIV testing were also cited in this study. These findings show the weakness of utilisation of VCT services by all persons. Thus, we call on researchers to focus their attention to revive the prevention of HIV and to strengthen the VCT services in fighting against the main engines of the increased vulnerability of the population in order to improve timely the HIV diagnosis and the therapeutic measures, to break the HIV transmission cycle, and improve the health of infected persons and achieve the objectives of the strategy for the acceleration of the UNAIDS.

\section{Conflict of interest}

The authors declare no potential conflicts of interest with respect to the research, authorship, and/or publication of this article.

\section{References}

1. UNAIDS, AIDS by the numbers, world day of AIDS 2015. Available at: http://www.unaids.org/sites/default/files/media_asset/AIDS_by_ the_numbers_2015_fr.pdf (Accessed: 3.03.2016).

2. Gilles Pialoux et France Lert, Rapport nouvelles méthodes de prévention et réduction des risques dans les groupes à haut risque visà-vis du VIH et des IST, 2010. Available at: http://vih.org/20100112/ nouvelles-methodes-prevention-et-reduction-risques/57351 (Accessed: 16.12.2016).

3. ONUSIDA, estimations VIH et SIDA en République démocratique du Congo, 2014. Available at: http://www.unaids.org/fr/regionscountries/countries/democraticrepublicofhecongo (Accessed: 15.11.2015).

4. Rapport d'activité sur la riposte au VIH/SIDA en R.D. Congo, Programme National Multisectoriel de Lutte contre le Sida, 2012. Available at: http://www.unaids.org/sites/default/files/en/dataanalysis/ knowyourresponse/countryprogressreports/2012countries/ce_ CD_Narrative_Report[1].pdf (Accessed: 15.11.2015).

5. Kautako-Kiambi M, Aloni-Ntetani M, Pululu P, et al. Socio-demographic, biological and clinical profile of patients living with HIV during screening in a voluntary counselling and screening centre in a rural area of Mbanza-Ngungu, Democratic Republic of Congo, in 2006-2011. Bull Soc Pathol Exot 2013; 106: 180-183.

6. Musafiri J, Mbayo PM, Bakaswa G, et al. HIV seroprevalence among tuberculous patients in Kisangani in the Democratic Republic of Congo. Santé Publique 2013; 25: 483-490.

7. Hayward P. Highlights from the seventh IAS Conference. Lancet Infect Dis 2013; 13: 659.

8. Tshingani K, Mukumbi H, Lubangi MM, et al. Comparative and evolutionary profile of people infected with HIV on antiretroviral therapy in Kinshasa, Democratic Republic of Congo. Pan Afr Med J 2014; 19: 388.

9. OMS/ONUSIDA, Guide du conseil et du dépistage du VIH à l'initiative du soignant dans les établissements de santé, Mai 2007.

10. Module 8: Prévention de l'infection à VIH dans: Prise en charge globale du VIH dans les pays à ressources limitées, Guide de formation à l'usage des paramédicaux par Bouchaud O, Tidiane Ndour C, édition doin, 2011. Available at: http://www.pathexo.fr/standard1600-1.html (Accessed: 10.10.2015).

11. Jean K. Testing the "Test and Treat" HIV prevention strategy: the example of Ivory Cost, Santé publique et épidémiologie. Université de Versailles-Saint Quentin en Yvelines, 2013. Available at: https://inriav3-preprod.archives-ouvertes.fr/tel-00964183v1 (Accessed: 16.10.2015).

12. Obermeyer CM, Bott S, Carrieri P, et al. HIV testing, treatment and prevention: generic tools for operational research. World Health Organization, Geneva 2009.

13. Carrizosa CM, Blumberg EJ, Hovell MF, et al. Determinants and prevalence of late HIV testing in Tijuana, Mexico. AIDS Patient Care STDS 2010; 24: 333-340.

14. Mukolo A, Villegas R, Aliyu M, et al. Predictors of Late Presentation for HIV Diagnosis: A Literature Review and Suggested Way Forward. AIDS Behav 2013; 17: 5-30.

15. Fonner VA, Denison J, Kennedy CE, et al. Voluntary counseling and testing (VCT) for changing HIV-related risk behavior in developing countries. Cochrane Database Syst Rev 2012; 9: CD001224.

16. Mulanga-Kabeya C, Nzilambi N, Edidi B, et al. Evidence of stable HIV seroprevalences in selected populations in the Democratic Republic of the Congo. AIDS 1998; 12: 905-910. 
17. Piot P, Quinn TC, Taelman H, et al. Acquired immunodeficiency syndrome in a heterosexual population in Zaire. Lancet 1984; 2 : 65-69.

18. Chadborn TR, Delpech VC, Sabin CA, et al. The late diagnosis and consequent short-term mortality of HIV-infected heterosexuals (England and Wales, 2000-2004). AIDS 2006; 20: 2371-2379.

19. Harries J, Cooper D, Myer L, et al. Policy maker and health care provider perspectives on reproductive decision-making amongst HIV-infected individuals in South Africa. BMC Public Health 2007; 7: 282.

20. Tshingani K, Schirvel C, Mukumbi H, et al. Vulnerability factors for malnutrition among people living with HIV under antiretroviral treatment in an outpatient clinic: Kinshasa, Democratic Republic of Congo. HIV AIDS Rev 2014; 13: 18-25.

21. DRC, Epidemiological fact sheet on HIV and AIDS, UNAIDS. WHO, Geneva 2008.

22. Bertrand JT, Brown LF, Kinzonzi M, et al. AIDS knowledge in three sites in Bas-Zaire. AIDS Educ Prev 1992; 4: 251-266.

23. Ngatu NR, Hirota R, Eitoku M, et al. Perception of the risk of sexual transmission of HIV among Congolese and Japanese university students. Environ Health Prev Med 2012; 17: 139-146.

24. Ryder RW, Batter V, Kaseka N, et al. Effect of HIV-1 infection on tuberculosis and fertility in a large workforce in Kinshasa, Democratic Republic of the Congo. AIDS Patient Care STDS 2000; 14: 297-304.

25. Kim AA, Malele F, Kaiser R, et al. HIV infection among internally displaced women and women residing in river populations along the Congo River, Democratic Republic of Congo. AIDS Behav 2009; 13: 914-920.

26. Rimoin AW, Hoff NA, Djoko CF, et al. HIV infection and risk factors among the armed forces personnel stationed in Kinshasa, Democratic Republic of Congo. Int J STD AIDS 2015; 26: 187-195.

27. Kayembe PK, Mapatano MA, Busangu AF, et al. Determinants of consistent condom use among female commercial sex workers in the Democratic Republic of Congo: implications for interventions. Sex Transm Infect 2008; 84: 202-206.

28. Weinhardt LS, Carey MP, Johnson BT, et al. Effects of HIV Counseling and Testing on Sexual Risk Behavior: A Meta-Analytic Review of Published Research, 1985-1997. Am J Public Health 1999; 89: 1397-1405.

29. Mwandagalirwa K, Jackson EF, McClamroch K, et al. Local differences in human immunodeficiency virus prevalence: a comparison of social venue patrons, antenatal patients, and sexually transmitted infection patients in eastern kinshasa. Sex Transm Dis 2009; 36: 406-412.

30. Zihindula G, Maharaj P. Risk of Sexual Violence: Perspectives and Experiences of Women in a Hospital in the Democratic Republic of Congo. J Community Health 2015; 40: 736-743.

31. Lusey H, San Sebastian M, Christianson M, et al. Conflicting discourses of church youths on masculinity and sexuality in the context of HIV in Kinshasa, Democratic Republic of Congo. SAHARA J 2014; 11: 84-93.

32. Vandepitte JM, Malele F, Kivuvu DM, et al. HIV and other sexually transmitted infections among female sex workers in Kinshasa, Democratic Republic of Congo, in 2002. Sex Transm Dis 2007; 34: 203-208.

33. Girardi E, Sabin CA, Monforte AD. Late diagnosis of HIV infection: epidemiological features, consequences and strategies to encourage earlier testing. J Acquir Immune Defic Syndr 2007; 46 Suppl 1: S3-S8.

34. Musheke M, Ntalasha H, Gari S, et al. A systematic review of qualitative findings on factors enabling and deterring uptake of HIV testing in Sub-Saharan Africa. BMC Public Health 2013; 13: 220.

35. Steward WT, Bharat S, Ramakrishna J, et al. Stigma is associated with delays in seeking care among HIV-infected people in India. J Int Assoc Provid AIDS Care 2013; 12: 103-109.
36. Meiberg AE, Bos AE, Onya HE, et al. Fear of stigmatization as barrier to voluntary HIV counseling and testing in South Africa. East Afr J Public Health 2008; 5: 49-54.

37. Palmer AK, Cescon A, Chan K, et al.; CANOC Collaboration. Factors associated with late initiation of highly active antiretroviral therapy among young HIV-positive men and women aged 18 to 29 years in Canada. J Int Assoc Provid AIDS Care 2014; 13: 56-62.

38. Maman S, Mbwambo J, Hogan NM, et al. Women's barriers to HIV1 testing and disclosure: Challenges for HIV-1 voluntary counselling and testing. AIDS Care 2001; 13: 595-603.

39. Mabunda G. Voluntary counselling and testing: Knowledge and practices in a rural South African village. J Transcult Nurs 2006; 17: 23-29.

40. Dodds C, Keogh P, Chime O, et al. Outsider status: Stigma and discrimination experienced by gay men and African people with HIV. Sigma Research, London 2004. 